\title{
PENGARUH SUMBER KARBON TERHADAP PRODUKSI BIOPLASTIK POLIHIDROKSIALKANOAT (PHA) DENGAN RALSTONIA EUTROPHA
}

\author{
Martha Aznury ${ }^{1}$, Tjandra Setiadi1*, dan Adi Pancoro ${ }^{2}$ \\ ${ }^{1}$ Kelompok Keahlian Mikrobiologi dan Bioproses Teknik Kimia \\ Program Studi Teknik Kimia, Fakultas Teknologi Industri \\ ${ }^{2}$ Kelompok Keahlian Mikrobiologi Genetika dan Biologi Molekuler \\ Sekolah Tinggi Ilmu Hayati \\ Institut Teknologi Bandung \\ Jalan Ganesha 10 Bandung 40132 \\ Email : tjandra@che.itb.ac.id
}

\begin{abstract}
Abstrak
Bioplastik polihidroksialkanoat (PHA) adalah bioplastik dari kelompok poliester dengan sifat fisikokimia mirip dengan plastik polipropilen dari minyak bumi. Penelitian ini bertujuan untuk mempelajari pengaruh sumber karbon terhadap poduksi PHA yang dilakukan dengan proses fermentasi menggunakan Ralstonia eutropha. Ralstonia eutropha dikultivasi dalam bioreaktor batch untuk mempelajari dinamika produksi kopolimer $\mathrm{P}(3 \mathrm{HB}-\mathrm{co}-3 \mathrm{HV})$ dari sumber karbon glukosa atau fruktosa, serta mempelajari pengaruh sumber stimulator asam lemak volatil. Kondisi operasional fermentasi menggunakan bioreaktor $7 \mathrm{~L}$ adalah pada temperatur $30{ }^{\circ} \mathrm{C}$ dan $\mathrm{pH}$ 7. Konsentrasi sumber karbon glukosa atau fruktosa yang digunakan adalah $40 \mathrm{gr} / \mathrm{L}$, dan setelah 20 jam fermentasi ditambahkan asam lemak volatil yang berfungsi sebagai stimulator dalam produksi P(3HB-co-3HV). Panen sel Ralstonia eutropha dilakukan setelah 60 jam. Hasil penelitian menunjukkan fermentasi Ralstonia eutropha dengan substrat fruktosa dan asam lemak volatil sebagai stimulator mempunyai kandungan PHA sebesar 32,78\%, dengan kadar HV 11,78\%. Pada pemberian substrat glukosa dan asam lemak volatil menunjukkan kandungan PHA sebesar 20,19\%, dengan kadar HV 8.71\%. Jadi fermentasi Ralstonia eutropha dengan menggunakan substrat fruktosa memberikan yield yang lebih tinggi dibandingkan menggunakan substrat glukosa.
\end{abstract}

Kata Kunci: Asam lemak volatil, fruktosa, glukosa, PHA, P(3HB-co-3HV), Ralstonia eutropha

\begin{abstract}
Bioplastic Polyhidroxyalknoate (PHA) is a polyester type bioplastic with physicochemical properties resemble to those of polypropilen from petroleum. PHA production was investigated to determine the effect of carbon source on the fermentation process by Ralstonia eutropha. Specifically, Ralstonia eutropha was cultivated in a batch bioreactor to show the dynamics of $\mathrm{P}(3 \mathrm{HB}-\mathrm{co}-3 \mathrm{HV})$ copolymer production from glucose or fructose as $\mathrm{C}$ source. In adition, the effect of volatile fatty acids addition, as stimulator to the copolymer production, was also studied. The operating conditions in a $7 \mathrm{~L} \mathrm{bioreactor} \mathrm{were} \mathrm{at}$ temperature $30{ }^{\circ} \mathrm{C}$ and $\mathrm{pH} 7.0$. The concentration of carbon source glucose or fructose was $40 \mathrm{~g} / \mathrm{L}$, and after 20 hour fermentation, volatile fatty acids were added. With volatile fatty acids addition, the resulting fructose fermentation had PHA content of $32.78 \%$, in which the HV percentage was $11.78 \%$. Meanwhile, the fermentation of glucose, stimulated by volatile fatty acids, gave PHA as much as $20.19 \%$ with $\mathrm{HV}$ percentage of $8.71 \%$. Therefore,, the Ralstonia eutropha fermentation of fructose as the carbon source gave a higher yield than glucose.
\end{abstract}

Keywords: Volatil Fatty Acid, Fructose, Glucose, PHA, P(3HB-co-3HV), Ralstonia eutropha

*korespondensi 


\section{Pendahuluan}

Di dunia kehidupan modern penggunaan plastik tidak dapat dipungkiri merupakan bagian dari kehidupan sehari-hari ada di sekeliling kita. Penggunaan di tingkat rumah tangga, industri automobil, industri telekomunikasi, industri pertanian, dan juga di bidang kesehatan. Plastik merupakan unsur utama atau bagian besar untuk alat-alat tersebut dibuat, seperti: peralatan kesehatan, peralatan dapur, peralatan kantor, dan lainlain. Material plastik yang umumnya digunakan adalah turunan dari minyak bumi, dengan seiringnya waktu terjadinya permasalahan di dalam bahan baku serta kemampuan plastik ini jika telah menjadi limbah. Pada tahun 1925 para ilmuwan telah memulai penelitian untuk mendapatkan palstik yang dapat didegradasi secara alami atau sering diebut dengan bioplastik.

Polihidroksialkanoat (PHA) adalah salah satu jenis plastik biodegradabel yang termasuk dalam kelompok poliester. PHA dapat terdegradasi sempurna dan memiliki sifat yang mirip dengan kelebihan yang dimiliki oleh plastik konvensional. Nilai tambah PHA dibandingkan dengan plastik biodegradabel lain adalah bahan bakunya selalu dapat diperbaharui (renewable), seperti glukosa, fruktosa dan asam lemak volatil.

Sekitar 300 bakteri penghasil PHA telah dikenal saat ini (Suriyamongkol dkk., 2007), akan tetapi hanya sedikit bakteri yang telah digunakan dalam produksi PHA secara industrial, salah satunya adalah Rasltonia eutropha. Dengan demikian pada penelitian awal, yang sedang dilakukan pada tahun 2009 dengan pembiayaan dari Hibah Penelitian Strategis Nasional DIKTI, bakteri Ralstonia eutropha digunakan dalam memproduksi bioplastik dengan sumber substrat yang dipakai adalah asam lemak volatil (ALV) sintetis.

Penelitian yang dilakukan ini merupakan kelanjutan dari penelitian tentang bioplastik. Penelitian terbaru menunjukkan bahwa beberapa stimulator tertentu seperti asetat asam oleat, dan propionat mempunyai pengaruh yang sangat positif dalam meningkatkan perolehan dan produktivitas (Lee dkk., 2000; Marangoni dkk, 2002; Khanna dan Srivastava, 2007).

Tujuan utama penelitian ini adalah untuk memproduksi bahan dasar plastik biodegradable PHA dari pengaruh sumber karbon melalui fermentasi Ralstonia eutropha.

\section{Teori Dasar}

Beberapa mikroorganisme mempunyai kemampuan di dalam memproduksi PHA di antara, Bacillus megaterium, Alcaligenes $s p$, Pseudomonas aeruginosa, Escherichia coli, dan Ralstonia eutropha. Fungsi PHA di dalam metabolisme mikroba itu sendiri adalah sebagai sumber energi dan makanan yang tersimpan di dalam sel. PHA lebih mendapatkan perhatian karena berpotensial sebagai bioplastik dengan sifat termoplastik dan elastomer. Ralstonia eutropha merupakan salah satu bakteri yang dapat memproduksi bioplastik dengan kandungan PHA yang tinggi dan berpotensial untuk dikembangkan secara komersil (Byrom, 1994).

Kandungan produksi dan bentuk PHA dari Ralstonia eutropha kemungkinan dapat dipengaruhi oleh sumber karbon dan adanya stimulator asam lemak volatil yang dapat membentuk kopolimer poli (3hidroksibutirat-cohidroksivalerat) P(3HB-co3HV) (Du dkk., 2001; Shang dkk., 2003; Volova dan Kalacheva, 2005). Penelitian ini menggunakan ALV sintetik yang merupakan asam volatil lemak (ALV) terdiri dari butirat, asetat, propionat, dan valerat berperan sebagai stimulator dalam proses fermentasi aerobik Ralstonia eutropha akan membentuk $\mathrm{P}(3 \mathrm{HB}-\mathrm{co}-3 \mathrm{HV})$.

Pemberian stimulator ALV pada saat fermentasi ditambahkan setelah Ralstonia eutropha mengalami fase pertumbuhan cepat. Fase pertumbuhan cepat ini, Ralstonia eutropha telah memproduksi PHB (polihidroksibutirat) tetapi belum dapat memproduksi 3HV. Produksi 3HV terjadi karena adanya kondesasi dari propional-coA dan asetilcoA yang dilakukan oleh enzim $\beta$ ketotiolase. Maka dari itu ALV baru dapat diberikan sebagai stimulator untuk memproduksi $3 \mathrm{HV}$ yang selanjutnya akan membentuk kopolimer P(3HB-co-3HV) (Patnaik 2005; Volova dan Kalacheva, 2005). Waktu pemberian dan banyaknya jumlah ALV akan sangat mempengaruhi persentase $\mathrm{P}(3 \mathrm{HB}-\mathrm{co}-3 \mathrm{HV})$ dan jenis kopolimer dari $\mathrm{P}(3 \mathrm{HB}-\mathrm{co}-\mathrm{x} \% 3 \mathrm{HV})$ yang terbentuk (Volova dan Kalacheva, 2005).

ALV sintetis yang digunakan adalah asam propionat dan asam asetat. Konsentrasi asam propionat yaitu $1,2 \mathrm{~g} / \mathrm{L}$ dan asam asetat 6,6 g/L yang didasarkan rujukan komposisi hasil fermentasi anaerobik air limbah industri kelapa sawit pada pH 7 (Hassan dkk., 1996). Pemberian ALV dilakukan setelah Ralstonia eutropha mengalami fase pertumbuhan cepat. 
Pengamatan dilakukan dengan melihat proses perkembangan jumlah berat sel kering terhadap waktu kultivasi.

\section{Metodologi}

\section{Bahan dan Alat}

$R$. eutropha JM 134 digunakan pada semua percobaan. Kultur di pelihara dalam nutrisi agar miring pada temperature $5^{\circ} \mathrm{C}$ dan setiap bulan diadakan peremajaan.

Sebuah media garam mineral terdiri atas: $2,0 \mathrm{~g} / \mathrm{L}\left(\mathrm{NH}_{4}\right)_{2} \mathrm{SO}_{4}: 2,0 \mathrm{~g} / \mathrm{L} \mathrm{KH}_{2} \mathrm{PO}_{4} ; 0,6$ $\mathrm{g} / \mathrm{L} \mathrm{Na} \mathrm{HPO}_{4} ; 0,2$ g/L MgSO $4.7 \mathrm{H}_{2} \mathrm{O} ; 20 \mathrm{mg} / \mathrm{L}$ $\mathrm{CaCl}_{2}, 10 \mathrm{~mL} / \mathrm{L}$ larutan trace metal, $0.1 \mathrm{~g} / \mathrm{L}$ ekstrak ragi digunakan. Larutan trace metal terdiri dari: $1,3 \mathrm{mg} / \mathrm{L} \mathrm{ZnSO}_{4} .7 \mathrm{H}_{2} \mathrm{O} ; 0,2 \mathrm{mg} / \mathrm{L}$

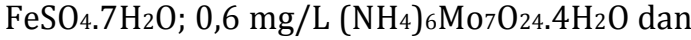
$0,6 \mathrm{mg} / \mathrm{L} \mathrm{H}_{3} \mathrm{BO}_{3}$. Fruktosa dan glukosa digunakan sebagai sumber karbon dengan konsentrasi $40 \mathrm{~g} / \mathrm{L}$ (Khanna dan Srivastava, 2005) sebagai media produksi dan perkembang biakkan inokulum. Fruktosa atau glukosa, ekstrak ragi, dan larutan garam disetrilisasi secara terpisah pada temperatur $121^{\circ} \mathrm{C}$ dan kemudian dicampur dengan inokulum secara aseptik. Sedangkan untuk pH diatur hingga mencapai 7 dengan menggunakan $2 \mathrm{~N} \mathrm{NaOH} / 2 \mathrm{~N} \mathrm{HCl}$.

Media yang digunakan pada percobaan semuanya sama hanya dibedakan pada sumber karbon fruktosa atau glukosa, sedangkan sumber nitrogen dari urea sama dengan konsentrasi $2 \mathrm{~g} / \mathrm{L}$.

\section{Metoda}

Pertumbuhan Ralstonia eutropha

Media garam mineral ditambahkan dengan konsentrasi fruktosa atau glukosa 40 $\mathrm{g} / \mathrm{L}$ digunakan untuk mengembangbiakkan inokulum. Mikroorganisme dikultivasi pada kecepatan agitasi $150 \mathrm{rpm}$ dan $30^{\circ} \mathrm{C}$ dan $\mathrm{pH} 7$ selama 20 jam dalam 2 L gelas Erlenmeyer 1,5 $\mathrm{L}$ media seperti di atas. Inokulum diberikan $10 \%$ dari total media yang diberikan. Lalu setiap jam dilihat pertumbuhan mikroba untuk melihat fase-fase perkembangan Ralstonia eutropha. Pertumbuhan sel dianalisa dengan menggunakan ukuran optikal densitas pada media kultur pada panjang gelombang $600 \mathrm{~nm}$.

Pengaruh perbedaan sumber karbon pada pertumbuhan dan produksi PHA

Media memproduksi PHA yang digunakan adalah fruktosa atau glukosa. Fruktosa atau glukosa sebagai variabel untuk melihat pengaruh dalam memproduksi PHA.
Media garam mineral dengan konsentrasi glukosa $40 \mathrm{~g} / \mathrm{L}$ digunakan untuk mengembang biakkan inokulum. Mikroorganisme dikultivasi pada kecepatan agitasi $150 \mathrm{rpm}$ dan $30^{\circ} \mathrm{C}$ dan $\mathrm{pH} 7$ selama 20 jam dalam $12 \mathrm{~L}$ bioreaktor dengan kandungan $7 \mathrm{~L}$ media seperti di atas. Inokulum diberikan $10 \%$ dari total media yang diberikan. Sedangkan pertambahan asam propionat dan asetat pada waktu dimana fase pertumbuhan cepat sedang berjalan. Konsentrasi asam propionat dan asam asetat yang dipergunakan mengikuti penelitian Hassan dkk. (1996) yaitu 6,6 g/L asam asetat dan 1,2 g/L asam propionat.

\section{Analisa PHA}

Pada penentuan konsentrasi PHA, biopolimer yang terdapat di dalam sel diekstraksi dengan penambahan natrium hipoklorit dan kloroform pada sel seperti yang dilakukan oleh Hahn dkk. (1993). PHA yang larut dalam kloroform dianalisa konsentrasinya dengan cara asam krotonik yang dilakukan oleh Slepecky (1969).

\section{Hasil dan Pembahasan \\ Dinamika pertumbuhan Ralstonia eutropha}

Pengamatan awal untuk pertumbuhan Ralstonia eutropha dengan melihat berat sel kering yang didapat dari perlakukan variabel stimulator dari ALV terhadap waktu. Gambar 1 menunjukkan dinamika berat sel kering dari Ralstonia eutropha terus meningkat dari bermacam variasi ALV.

Penambahan stimulator ALV pada jam ke 20, untuk melihat peningkatan dan waktu yang terbaik didalam proses pemanenan sel, menunjukkan keempat variasi di atas, waktu ke 60 jam adalah optimum sel dapat berkembang. Sehingga waktu yang terbaik untuk melakukan panen mikroba Ralstonia eutropha adalah di 60 jam masa kultivasi.

Komposisi ALV 6,6 g/L asam asetat dan $1,2 \mathrm{~g} / \mathrm{L}$ asam propionat yang menunjukkan peningkatan pada berat sel kering. Penelitian dilanjutkan untuk mengamati kandungan PHA dari komposisi ALV 6,6 g/L asam asetat dan $1,2 \mathrm{~g} / \mathrm{L}$ asam propionat dengan waktu panen 60 jam.

Pengaruh substrat dan stimulator

Penelitian dilanjutkan dengan melakukan perbedaan subtrat dalam pertumbuhan awal Ralstonia eutropha yaitu mengubah substrat dari fruktosa menjadi glukosa dengan konsentrasi yang sama 40 
g/L. Konsentrasi substrat $40 \mathrm{~g} / \mathrm{L}$ didasarkan pada komposisi optimum produksi PHA dengan fermentasi Ralstonia eutropha (Khanna dan Srivastava, 2005).

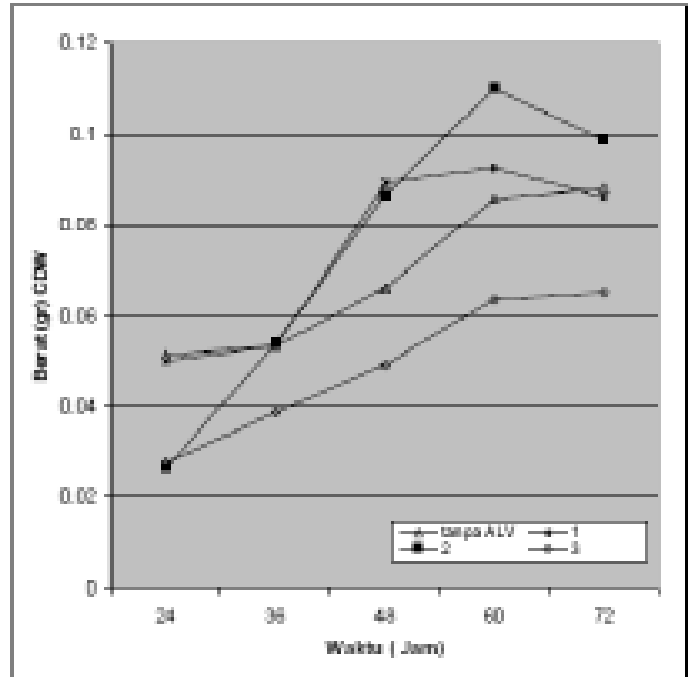

Gambar 1. Dinamika pertumbuhan Ralstonia eutropha dilihat dari berat sel kering, waktu fermentasi dan variasi Asam lemak volatill sintetik (asam asetat dan asam propionat)

(1) $3,3 \mathrm{~g} / \mathrm{L}$ as. asetat; $0,6 \mathrm{~g} / \mathrm{L}$ as. propionat;

(2) $6,6 \mathrm{~g} / \mathrm{L}$ as. asetat; $1,2 \mathrm{~g} / \mathrm{L}$ as. propionat;

(3) $10 \mathrm{~g} / \mathrm{L}$ as. asetat; $4 \mathrm{~g} / \mathrm{L}$ as. propionat; kons. $40 \mathrm{~g} / \mathrm{L}$ fruktosa

Tabel 1. Pengaruh perbedaan subtrat dan stimulator terhadap kandungan PHA

\begin{tabular}{lccc}
\hline \multicolumn{1}{c}{ Sampel } & $\begin{array}{c}\text { Berat } \\
\text { Sel } \\
\text { Kering } \\
\text { (BSK) } \\
\text { (g/L) }\end{array}$ & $\begin{array}{c}\text { Kons. } \\
\text { PHB } \\
\text { (g/L) }\end{array}$ & $\begin{array}{c}\text { Kand. } \\
\text { PHA } \\
(\%)\end{array}$ \\
\hline $\begin{array}{l}\text { Fruktosa } \\
\begin{array}{l}\text { Fruktosa 6,6 g/L } \\
\text { as. asetat; 1,2 g/L } \\
\text { as.propionat }\end{array}\end{array}$ & 12,99 & 4,26 & 32,78 \\
$\begin{array}{l}\text { Glukosa } \\
\text { Glukosa 6,6 g/L } \\
\text { as. asetat; 1,2 g/L } \\
\text { as.propionat }\end{array}$ & 21,30 & 1,79 & 8,40 \\
\hline
\end{tabular}

Pengaruh sumber karbon yang berbeda antara fruktosa dan glukosa (Tabel 1) terhadap produksi PHA terlihat dari jumlah kandungan PHA. Substrat fruktosa menghasilkan persentase kandungan PHA $12,31 \%$ sedangkan substrat glukosa mendapatkan kandungan PHA 8,40\%.

Efek pertambahan stimulator asam propionat dan asam asetat dengan sumber karbon fruktosa atau glukosa menunjukkan peningkatan pada kandungan PHA. Sumber karbon fruktosa dan stimulator yang ditambahkan pada waktu ke 20 menghasilkan $32,78 \%$ dan sumber karbon glukosa dan stimulator menghasilkan 20,19\%. Sehingga dapat dinyatakn bahwa sumber karbon fruktosa dapat meningkatkan kandungan PHA.

Pengamatan presentase kandungan kopolimer $\mathrm{P}(3 \mathrm{HB}-\mathrm{co}-3 \mathrm{HV})$ dengan meninjau dari titik leleh dengan perbandingan dari standar PHA (Tabel 2) yang telah dimiliki Laboratorium Mikrobiologi dan Teknologi Bioproses Teknik Kimia ITB.

\begin{tabular}{|c|c|c|}
\hline Sampel & $3 \mathrm{HV}(\%)$ & $\begin{array}{c}\text { Titik } \\
\text { leleh }{ }^{\circ} \mathrm{C}\end{array}$ \\
\hline Fruktosa & 0,1 & 169,8 \\
\hline $\begin{array}{l}\text { Fruktosa } 6,6 \mathrm{~g} / \mathrm{L} \text { as. } \\
\text { asetat; } 1,2 \mathrm{~g} / \mathrm{L} \\
\text { as.propionat }\end{array}$ & 11,78 & 156 \\
\hline Glukosa & 0,1 & 169,8 \\
\hline $\begin{array}{l}\text { Glukosa } 6,6 \mathrm{~g} / \mathrm{L} \text { as. } \\
\text { asetat; } 1,2 \mathrm{~g} / \mathrm{L} \\
\text { as.propionat }\end{array}$ & 8,71 & 160 \\
\hline
\end{tabular}

Penambahan asam propionat dan asam asetat memicu terbentuknya hidroksi valerat (HV), sehingga dengan penambahan stimulator ALV ini akan membentuk kopolimer dari hidroksi butirat (HB) dan HV. Untuk mengetahui persentase HV yang terbentuk dibandingkan dengan titik leleh PHA standar yang masing-masing menggandung persentase HV 0\%, 5\%, 19\% dan 30\%. Hasil pengamatan titik leleh sampel menyimpulkan pada stimulator ALV pada subtrat fruktosa mendapatkan komposisi $11,78 \%$ HV dan sumber karbon glukosa dan stimulator ALV mengandung komposisi 8,71\% HV. Sedangkan sampel tanpa asam lemak volatil menunjukkan hanya $0,1 \% 3 \mathrm{HV}$, ini menandakan fruktosa atau glukosa hanya dapat memproduksi PHB. Adanya pengaruh perbedaan sumber karbon dan stimulator terhadap presentase HV untuk membentuk kopolimer, didasarkan adanya kondesasi dari propional-coA dan asetil-coA yang dilakukan oleh enzim $\beta$-ketotiolase.

\section{Kesimpulan}

Dari hasil penelitian dan pembahasan yang telah dilakukan dapat diambil kesimpulan sebagai berikut : 
1. Waktu panen fermentasi Ralstonia eutropha adalah 60 jam setelah dikultivasi.

2. Komposisi ALV adalah 6,6 g/L asam asetat dan $1,2 \mathrm{~g} / \mathrm{L}$ asam propionat.

3. Sumber karbon fruktosa ( $40 \mathrm{~g} / \mathrm{L}$ ) dan ALV mendapatkan kandungan 32,78\% PHA.

4. Sumber karbon glukosa ( $40 \mathrm{~g} / \mathrm{L}$ ) dan ALV mendapatkan kandungan 20,19\% PHA.

5. Sampel fruktosa dan ALV mempunyai komposisi 11,78\% HV.

6. Sampel glukosa dan ALV mempunyai komposisi 8,71\% HV.

\section{Ucapan Terima Kasih}

Penulis menyampaikan terima kasih kepada Dikti memberikan bantuan dana penelitian dalam proyek Hibah Penelitian Strategis Nasional DIKTI 2009 yang berjudul Produk Bioplastik dari Air Limbah Industri Kelapa Sawit Menggunakan Ralstonia eutropha.

\section{Daftar Pustaka}

Byrom, D., Polyhydroxyalkanoates, In: Mobley $D P$ (ed) plastic from microbes: microbial synthesis of polymers and polymers precursors, 1994, Hanser, Munich, p. 5-33.

Du, G. C.; Chen, J.; Yu,J.; Lun, S., Feeding strategy of propionic acid for production of poly(3-hydroxybutyrate-co-3-hydroxyvalerate) with Ralstonia eutropha, Biochemical Engineering Journal, 2001, Vol. 8(2), 103-110.

Hassan, M. A.; Shirai, Y.; Kusubayashi, N.; Karim, M. I. A.; Nakanishi, K.; Hashimoto, K., Effect of Organic Acid Profiles during Anaerobic Treatment of Palm Oil Mill Effluent on the Production of Polyhydroxyalkanoates by Rhodobacter sphaeroides, Journal of Fermentation and Bioengineering, 1996, Vol. 82(2), 151-156.

Khanna, S.; Srivastava, A. K., Statistical media optimization studies for growth and PHB production by Ralstonia eutropha, Process Biochemistry, 2005,Vol. 40(6), 2173-2182.
Khanna, S.; Srivastava, A. K., Production of Poly (3-Hydroxybutyricco-3-Hydroxyvaleric Acid) Having a High Hydroxyvalerate Content with Valeric Acid Feeding, Journal of Industrial Microbiology Biotechnology, 2007,Vol. 34(6), 457-461.

Lee, Y.; Kang, M.; Jung,Y., Regulating the Molar Fraction of 4-Hydroxybutyrate in Poly(3Hydroxybutyrate-4-hydroxybutyrate)

Biosynthesis by Ralstonia eutropha Using Propionate as a Stimulator, Journal of Bioscience and Bioengineering, 2000, Vol. 89(4), 380-383.

Shang, L.; Jiang, M.; Chang, H. N., Poly(3hydroxybutyrate) synthesis in fed-batch culture of Ralstonia eutropha with phosphate limitation under different glucose concentrations, Biotechnology Letters, 2003, Vol. 25(17), 1415-1419.

Marangoni, C.; Furigo Jr., A.; de Aragao, G. M., Production of poly(3-hydroxybutyrate-co-3hydroxyvalerate) by Ralstonia eutropha in whey and inverted sugar with propionic acid feeding, Process Biochemistry, 2002, Vol. 38(2), 137-141.

Patnaik, P. R., Perspectives in the Modeling and Optimization of PHB Production by Pure and Mixed Cultures, Critical Reviews in Biotechnology, 2005, Vol. 25(3), 153-171.

Suriyamongkol, P.; Weselake, R.; Narine S.; Moloney, M.; Shah, S., Biotechnological Approaches for The Production of Polyhydroxyalkanoates in Microorganisms and Plants: A Review, Biotechnology Advances, 2007, Vol. 25(2), 148-175.

Volova, T. G.; Kalacheva, G. S., The Synthesis of Hydroxybutyrate and Hydroxyvalerate Copolymers by the Bacterium Ralstonia eutropha, Microbiology, 2005, Vol. 74(1), 5459. 